\title{
The Novel GRN g.1159_1160delTG Mutation is Associated with Behavioral Variant Frontotemporal Dementia
}

\author{
Alberto Calvi ${ }^{\mathrm{a}, 1}$, Sara M.G. Cioffi ${ }^{\mathrm{a}, 1}$, Paolo Caffarra ${ }^{\mathrm{b}, \mathrm{c}}$, Chiara Fenoglio ${ }^{\mathrm{a}}$, Maria Serpente ${ }^{\mathrm{a}}$, \\ Anna M. Pietroboni ${ }^{\mathrm{a}}$, Andrea Arighi ${ }^{\mathrm{a}}$, Laura Ghezzi ${ }^{\mathrm{a}}$, Simona Gardini ${ }^{\mathrm{b}}$, Elio Scarpini ${ }^{\mathrm{a}}$ \\ and Daniela Galimberti ${ }^{\mathrm{a}, *}$ \\ ${ }^{a}$ Neurology Unit, Department of Pathophysiology and Transplantation, University of Milan, Fondazione Ca' \\ Granda, IRCCS Ospedale Policlinico, Milan, Italy \\ ${ }^{\mathrm{b}}$ Department of Neurosciences, University of Parma, Parma, Italy \\ ${ }^{\mathrm{c} C e n t e r ~ f o r ~ C o g n i t i v e ~ D i s o r d e r s, ~ A U S L, ~ P a r m a, ~ I t a l y ~}$
}

Handling Associate Editor: Beatrice Arosio

Accepted 23 August 2014

\begin{abstract}
Mutations in progranulin gene $(G R N)$ are a common cause of autosomal dominant frontotemporal lobar degeneration and are associated with a wide phenotypic heterogeneity. Here, we describe two probands with behavioral variant frontotemporal dementia with a novel mutation in this gene (1159_1160delTG). Both had a positive family history for dementia and showed atypical features at imaging. Their progranulin plasma levels were undetectable, and the mutation was not present in cDNA, suggesting haploinsufficiency. Progranulin levels were low even in asymptomatic carriers of the variant. Results described enlarge current knowledge on genetic causes of the disease and clinical characteristics of carriers.
\end{abstract}

Keywords: Deletion, frontotemporal dementia, haploinsufficiency, mutation, progranulin $(G R N)$

\section{INTRODUCTION}

Frontotemporal lobar degeneration (FTLD) is recognized as one of the more common type of presenile dementia, accounting for $8-10 \%$ of all dementia patients [1], with a prevalence of about $4-15$ cases per 100,000 [2]. The disease manifests with different clinical syndromes: behavioral variant (bvFTD) and two syndromes affecting mainly the language, seman-

\footnotetext{
${ }^{1}$ These authors contributed equally to this work.

*Correspondence to: Daniela Galimberti, Neurology Unit, Department of Pathophysiology and Transplantation, University of Milan, Fondazione Ca' Granda, IRCCS Ospedale Policlinico, via F. Sforza, 35, 20122, Milan, Italy. Tel.: +390255033847; Fax: +390255036580; E-mail: daniela.galimberti@unimi.it.
}

tic dementia (SD) and progressive non-fluent aphasia (PNFA). There is a familial history in nearly one third to a half of the cases, where it is possible to recognize an autosomal dominant pattern of inheritance [3]. To date, there are three main genetic causes of familial FTLD: Microtubule Associated Protein Tau gene $(M A P T)$, progranulin $(G R N)$, both located on chromosome 17, and the hexanucleotide repeat expansion in the Open Reading Frame 72 gene in chromosome 9 (C9ORF72). The pathology includes two main patterns: tau deposition (FTLD-Tau), which is typically found in subjects carrying MAPT mutations, and immunoreactivity for ubiquitin (FTLD-U). The latter is split in different entities depending on the major protein present. TAR DNA binding Protein (TDP)-43 
is found in the majority of the non-tau pathological pattern, including GRN and C9ORF72 mutated subjects (see [4] for review).

GRN mutations are found in 5-20\% of FTLD familial cases and $1-5 \%$ of sporadic cases [5]. The gene is located on chromosome 17q21 and is composed by 13 exons encoding for progranulin, a cysteine-rich growth factor which is secreted and cleaved in several fragments (granulins). It is expressed in multiple tissues of the body and it has pleiotropic actions, including functions related to neural proliferation, survival, and inflammation.

The majority of genetic defects in $G R N$ are lossof-function mutations, causing haploinsufficiency, and are associated with extremely low plasma progranulin levels [6, 7]. The penetrance of $G R N$ mutations is incomplete and this condition is probably due to the presence of other genes influencing the manifestation of the disease. In this regard, TransMEMbrane (TMEM)106B, coding for a transmembrane protein that associate with progranulin in endo-lysosomes, has been recently identified as a disease modifier in GRN mutation carriers [8].

The clinical presentation associated with GRN mutations is extremely heterogeneous in terms of symptoms, disease duration, and age of onset. Patients usually present with any of the defined syndromes of FTLD, but in some cases there is prominent involvement of the extrapyramidal and motor systems, showing a clinical picture of a corticobasal syndrome, supranuclear palsy, or FTD with motor neuron disorders [9]. Typical neuroimaging in GRN mutation carriers consists of asymmetric brain atrophy with additional features such as asymmetric damage to white matter, severe cortical atrophy, and parietal lobe involvement. Here, we describe two families with a novel mutation in GRN. Probands, both with positive family history for dementia, developed FTD and showed very low plasma levels and atypical imaging features.

\section{CASE REPORTS}

\section{Patient \#1}

According to his relatives, Patient \#1 developed mild language deficits together with disinhibition and apathy at the age of 68 . One year later, he showed cognitive decline, markedly altered behavior, and a reduced function in daily-working activities. In addition, he manifested sleep disturbances, visual disperceptions and falls, requiring access to the emergency department, from which he was directed to our Neurology unit.

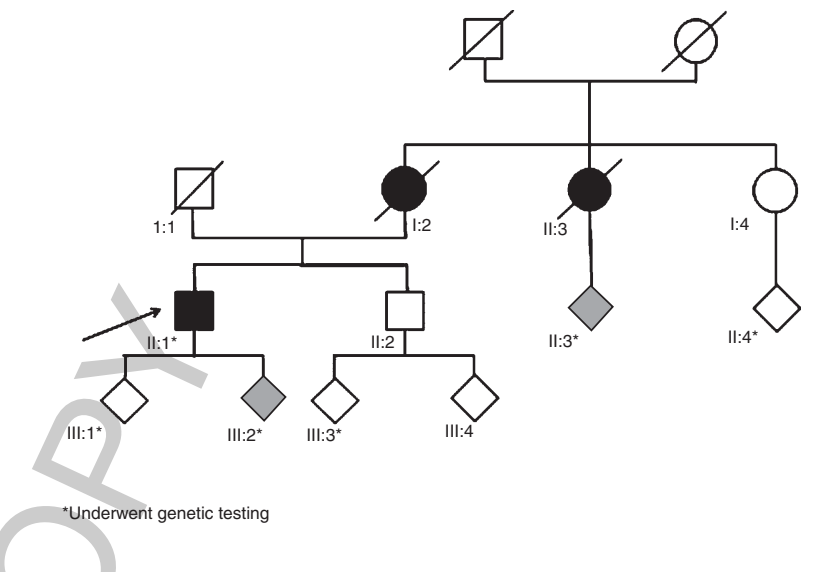

Fig. 1. Pedigree of patient \#1 (arrow). Square indicate males, circles females; diamonds are used instead to avoid disclosing sex in non-affected individuals. Black indicates symptomatic subjects, gray presymptomatic, and white asymptomatic. Bars indicate deceased family members.

His family history was positive for dementia, as his mother and maternal aunt were diagnosed with dementia in their seventies (Alzheimer's disease and Lewy body dementia, respectively) (Fig. 1, I:2, I:3).

The collection of anamnestic information revealed arterial hypertension, arterial vasculopathy with femoral and carotid stenosis, dyslipidemia, obstruction sleep apnea syndrome, and prostatic hypertrophy. During the medical evaluation, he showed disinhibited behavior and lack of attention. In addition, sexual disinhibition and hyperorality were reported by his wife. The neurological examination was unremarkable, except for the evidence of primitive reflexes and an initial mild gait ataxia, whereas no language impairment was observed. At neuropsychological testing, the patient scored 28/30 on MMSE (normal memory, language, and visuo-spatial functions) showing global efficiency in cognition associated with behavioral disturbances, disinhibition, and poor social judgment. Furthermore, the patient history outlined an insufficient performance in daily self-care activities $(\mathrm{ADL}=5 / 6, \mathrm{IADL}=2 / 8)$.

Axial T1-weighted scans at the magnetic resonance imaging (MRI) showed asymmetric frontal and temporal cortical atrophy (right $>$ left) (Fig. 2A). The coronal T1-weighted scan documented asymmetric temporal atrophy (right $>$ left) (Fig. 1C). $\left[{ }^{18} \mathrm{~F}\right]$-Fludeoxyglucose positron emission tomography (FDG-PET) showed bilateral frontal and temporal hypometabolism (Fig. 2B). Cerebrospinal fluid (CSF) biomarkers were normal (amyloid- $\beta=731 \mathrm{pg} / \mathrm{ml}$; $\operatorname{tau}=181 \mathrm{pg} / \mathrm{ml} ;$ Ptau $=29 \mathrm{pg} / \mathrm{ml}$ ). As the patient did 
A

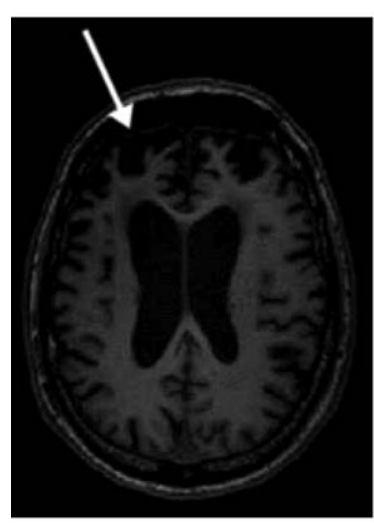

B

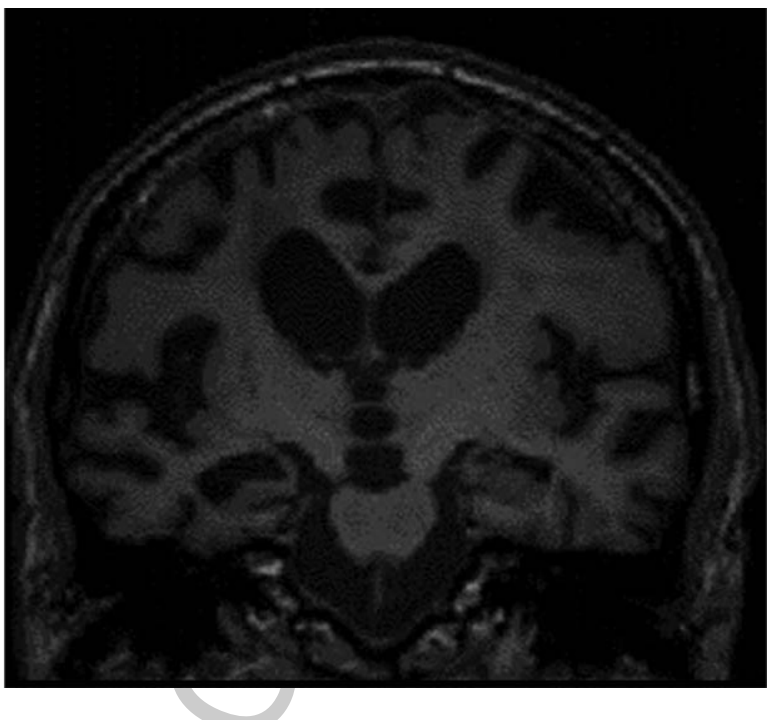

Fig. 2. MRI of patient \#1. A) Axial T1-weighted MRI scan documenting asymmetric frontal cortical atrophy (arrow) and temporal cortical atrophy (right $>$ left); B) coronal T1-weighted MRI scan documenting asymmetric temporal atrophy (right $>$ left).

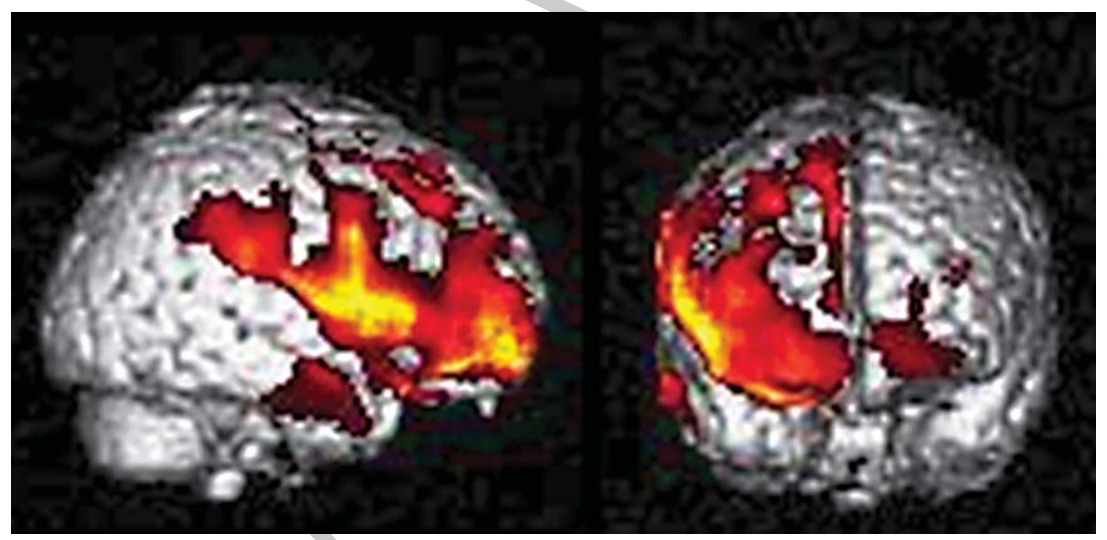

Fig. 3. FDG-PET of patient \#2, showing areas of hypometabolism mainly on the right side in fronto-temporal regions and thalamus and frontal cortex and insula $(p=0.001)$.

not show clinical symptoms and signs suggesting motor neuron disease, the electromyography was not carried out.

\section{Patient \#2}

Patient \#2, a male, began presenting with loss of inhibitory control, relevant mood alterations related to emotional lability, anedonia, apathy, depressive mood, anosognosia, and loss of hobbies and personal interests at the age of 66. The onset of symptoms started after retirement and they progressively worsened, with the addition of cognitive deficits of language (anomia, dysarthria, and stutter), memory and difficulties in the spatial orientation. He also suffered from mild dysphagia both for solid and liquid foods. Neuropsychological assessment showed normal global cognitive profile (MMSE 28/30) with partially reduced dailyliving activities (ADL 5/6, IADL 4/5) and scores under the normality threshold in praxis and attention. He suffered from hypertension and extrapyramidal signs lateralized on the left side. His family history was positive for FTD (father and sister). Electromyography and magnetic evoked potentials were normal, while brain CT showed bilateral temporal ventricular atrophy. The patients refused the lumbar puncture and MRI examination. Brain FDG-PET, using SPM5 software (Supplementary Materials), showed areas of 

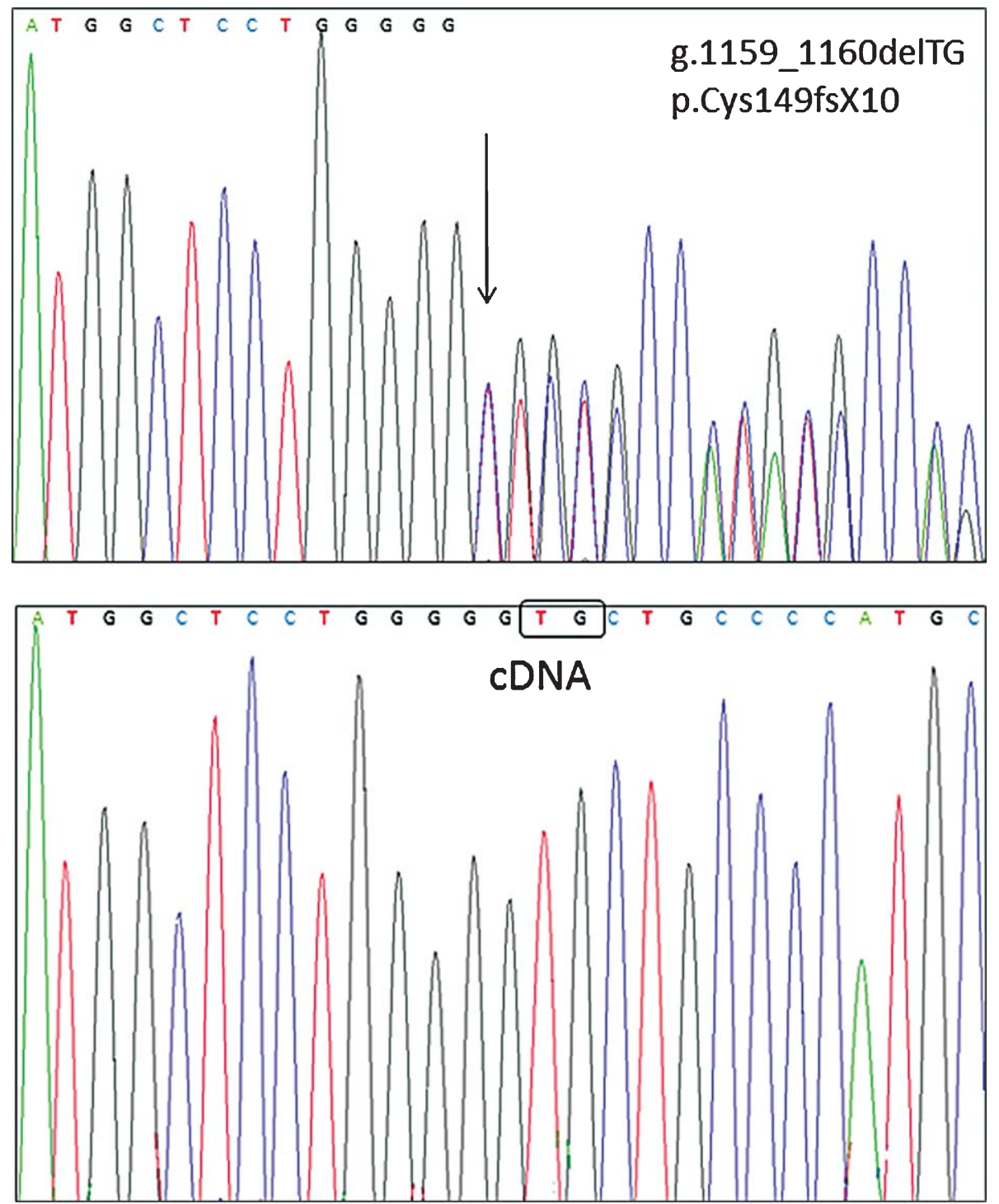

Fig. 4. Electropherogram of the DNA (top) and cDNA (bottom).

hypometabolism mainly on the right side in frontotemporal regions and thalamus, in bilateral superior frontal gyrus and left insula ( $p=0.001)$ (Fig. 3).

\section{METHODS AND RESULTS}

Both patients met the criteria for bvFTD [10]. In both probands, progranulin plasma levels, evaluated through an ELISA kit (Adipogene, Korea) after the ethical committee approval and patients' consent, were below the detection threshold $(<15 \mathrm{ng} / \mathrm{ml})$.

Therefore, we sequenced $(G R N)$ and found a novel mutation in exon 5: g.1159_1160delTG, that leads to a frameshift, which in turn creates a stop codon (c.445_446delTG, p.Cys 149fsX10).

The mutation was not observed in the cDNA isolated from peripheral blood cells, thus confirming that the aberrant mRNA is degraded through nonsense mediated decay (Fig. 4).

Additional family members of Patient \#1 were asymptomatic carriers of the mutation (Fig. 1A, III:2 and II:3 age 37 and 50 years, respectively). Both of them had plasma progranulin levels under the detection threshold (61 pg/ml) [11], whereas subjects III:1 and II:4, who did not carry the mutation, had normal progranulin plasma levels. Relatives of patient \#2 did not give informed consent for blood collection. 


\section{DISCUSSION}

Here, we described two patients with FTD carrying a novel mutation in $G R N$. Both families originate from the same region (central Italy), suggesting that they could derive from the same founder. Nevertheless, we did not have a large population to carry out a haplotype analysis.

So far, 69 different pathogenic mutations in $G R N$ have been described, including about ten dinucleotide deletions (http://www.molgen.vib-ua.be). The most common associated clinical phenotype is FTD, although corticobasal syndrome has been reported as well [12]. Regarding patients we described, both of them showed a typical behavioral syndrome, but patient \#1 developed, in addition, visual disperceptions and falls. Notably, his aunt was diagnosed with Lewy body dementia more than ten years before, due to the development of dementia, falls, and hallucinations, and died a few years later.

Progranulin plasma levels were undetectable, even in presymptomatic carriers, suggesting that biological changes associated with the mutation occur soon before clinical manifestations of the disease, and supporting the hypothesis that plasma progranulin evaluation could be a very good biomarker for identifying potential carriers. In accordance with MRI data on other $G R N$ mutation carriers, this new variant showed asymmetrical atrophy (see [13] for review). In spite of the marked atrophy, CSF biomarkers were normal, including tau protein, which is supposed to reflect the degree of neurodegeneration. This observation is in line with previous data [14] and suggests cautiousness in the interpretation of an apparently normal CSF picture.

In conclusion, although further studied on other family members will be needed to demonstrate the segregation of the genetic defect with the disease, the evidence of very low plasma progranulin levels together with the mRNA nonsense mediated decay strongly support the hypothesis that the variant is pathogenic and cause haploinsufficiency.

\section{ACKNOWLEDGMENTS}

This research was supported by Fondazione Monzino and Italian Ministry of Health (Ricerca Corrente to ES and Ricerca Finalizzata 2010-2311041 to PC).

Authors' disclosures available online (http://www.jalz.com/disclosures/view.php?id=2519).

\section{SUPPLEMENTARY MATERIAL}

The supplementary material is available in the electronic version of this article: http://dx.doi.org/ 10.3233/JAD-141380

\section{REFERENCES}

[1] Kirshner HS (2014) Frontotemporal dementia and primary progressive aphasia, a review. Neuropsychiatr Dis Treat 10, 1045-1055.

[2] Rabinovici GD, Miller BL (2010) Frontotemporal lobar degeneration: Epidemiology, pathophysiology, diagnosis and management. CNS Drugs 24, 375-398.

[3] Rohrer JD, Guerreiro R, Vandrovcova. J, Uphill J, Reiman D, Beck J, Isaacs AM, Authier A, Ferrari R, Fox NC, Mackenzie IRA,Warren JD, de Silva R, Holton J, Revesz T, Hardy J, Mead S, Rossor MN (2009) The heritability and genetics of frontotemporal lobar degeneration. Neurology $\mathbf{7 3}$, 1451-1456.

[4] Cerami C, Scarpini E, Cappa SF, Galimberti D (2012) Frontotemporal lobar degeneration: Current knowledge and future challenges. J Neurol 259, 2278-2286.

[5] Gijselinck I, van der Zee J, Engelborghs S, Goossens D, Peeters K, Mattheijssens M, Corsmit E (2008) Progranulin locus deletion in frontotemporal dementia. Hum Mutat 29, 53-58.

[6] Pietroboni AM, Fumagalli GG, Ghezzi L, Fenoglio C, Cortini F, Serpente M, Cantoni C, Rotondo E, Corti P, Carecchio M, Bassi M, Bresolin N, Galbiati D, Galimberti D, Scarpini E (2011) Phenotypic heterogeneity of the GRN Asp22fs mutation in a large Italian kindred. J Alzheimers Dis 24, 253-259.

[7] Carecchio M, Galimberti D, Fenoglio C, Serpente M, Scarpini E, Comi C, Terazzi E, Cantello R (2012) Evidence of presynaptic dopaminergic deficit in a patient with a novel progranulin mutation presenting with atypical parkinsonism. J Alzheimers Dis 38, 747-752.

[8] Finch N, Carrasquillo MM, Baker M, Rutherford NJ, Coppola G, Dejesus-Hernandez M, Crook R, Hunter T, Ghidoni R, Benussi L, Crook J, Finger E, Hantanpaa KJ, Karydas AM, Sengdy P, Gonzalez J, Seeley WW, Johnson N, Beach TG, Mesulam M, Forloni G, Kertesz A, Knopman DS, Uitti R, White CL, 3rd, Caselli R, Lippa C, Bigio EH, Wszolek ZK, Binetti G, Mackenzie IR, Miller BL, Boeve BF, Younkin SG, Dickson DW, Petersen RC, Graff-Radford NR, Geschwind DH, Rademakers R (2011) TMEM106B regulates progranulin levels and the penetrance of FTLD in GRN mutation carriers. Neurology 76, 467-474.

[9] López de Munain A, Alzualde A, Gorostidi A, Otaegui D, Ruiz-Martínez J, Indakoetxea B, Ferrer I, Pérez-Tur J, Sáenz A, Bergareche A, Barandiarán M, Poza JJ, Zabalza R, Ruiz I, Urtasun M, Fernández-Manchola I, Olasagasti B, Espinal JB, Olaskoaga J, Ruibal M, Moreno F, Carrera N, Massó JF (2008) Mutations in progranulin gene: Clinical, pathological, and ribonucleic acid expression findings. Biol Psychiatry 63, 946-952.

[10] Rascovsky K, Hodges JR, Knopman D, Mendez MF, Kramer JH, Neuhaus J, van Swieten JC, Seelaar H, Dopper EG, Onyike CU, Hillis AE, Josephs KA, Boeve BF, Kertesz A, Seeley WW, Rankin KP, Johnson JK, Gorno-Tempini ML, Rosen H, Prioleau-Latham CE, Lee A, Kipps CM, Lillo P, Piguet O, Rohrer JD, Rossor MN, Warren JD, Fox NC, 
Galasko D, Salmon DP, Black SE, Mesulam M, Weintraub S, Dickerson BC, Diehl-Schmid J, Pasquier F, Deramecourt V, Lebert F, Pijnenburg Y, Chow TW, Manes F, Grafman J, Cappa SF, Freedman M, Grossman M, Miller BL (2011) Sensitivity of revised diagnostic criteria for the behavioural variant of frontotemporal dementia. Brain 134, 2456-2477.

[11] Ghidoni R, Benussi L, Glionna M, Franzoni M, Binetti G (2008) Low plasma progranulin levels predict progranulin mutations in frontotemporal lobar degeneration. Neurology 71, 1235-1239.

[12] Yu CE, Bird TD, Bekris LM, Montine TJ, Leverenz JB, Steinbart E, Galloway NM, Feldman H, Woltjer R, Miller CA, Wood EM, Grossman M, McCluskey L, Clark CM, Neumann M, Danek A, Galasko DR, Arnold SE, Chen-
Plotkin A, Karydas A, Miller BL, Trojanowski JQ, Lee VM, Schellenberg GD, Van Deerlin VM (2010) The spectrum of mutations in progranulin: A collaborative study screening 545 cases of neurodegeneration. Arch Neurol 67, 161-170.

[13] Rohrer JD, Warren JD (2011) Phenotypic signatures of genetic Frontotemporal dementia. Curr Opin Neurol 24, 542545.

[14] Carecchio M, Fenoglio C, Cortini F, Comi C, Benussi L, Ghidoni R, Borroni B, De Riz M, Serpente M, Cantoni C, Franceschi M, Albertini V, Monaco F, Rainero I, Binetti G, Padovani A, Bresolin N, Scarpini E, Galimberti D (2011) Cerebrospinal fluid biomarkers in progranulin mutations carriers. J Alzheimers Dis 27, 781-790. 